\title{
Enzymatic phosphorylation of hair keratin enhances fast adsorption of cationic moieties
}

\author{
Vadim Volkov, Artur Cavaco-Paulo* \\ Centro de Engenharia Biológica (CEB), Universidade do Minho, Campus de Gualtar, 4710-057 Braga, Portugal
}

\section{A R T I C L E I N F O}

\section{Article history:}

Received 29 October 2015

Received in revised form

24 December 2015

Accepted 26 December 2015

Available online 3 January 2016

\section{Keywords:}

Hair keratin

Methylene blue

Phosphorylation

\begin{abstract}
A B S T R A C T
The current study describes the in vitro phosphorylation of a human hair keratin, using protein kinase for the first time. Phosphorylation of keratin was demonstrated by ${ }^{31} \mathrm{P}$ NMR (Nuclear Magnetic Resonance) and Diffuse Reflectance Infrared Fourier Transform (DRIFT) techniques. Phosphorylation induced a 2.5 fold increase of adsorption capacity in the first $10 \mathrm{~min}$ for cationic moiety like methylene blue (MB). Thorough description of MB adsorption process was performed by several isothermal models. Reconstructed fluorescent microscopy images depict distinct amounts of dye bound to the differently treated hair. The results of this work suggest that the enzymatic phosphorylation of keratins might have significant implications in hair shampooing and conditioning, where short application times of cationic components are of prime importance.
\end{abstract}

(c) 2015 Elsevier B.V. All rights reserved.

\section{Introduction}

Hard keratins are the basic building blocks found in human and animal hair, as well as nails, horns and feathers [1]. Apart of being a major target of the cosmetic and care products industry $[2,3]$, keratin fibers are lately being reported as novel biocompatible materials in the areas of tissue engineering [4], wound dressings [5], surgical interventions [6], among others. Keratin and keratin-derived products may also be used as adsorbents for (toxic) pollutants [7-9]. For those purposes keratin structure may be chemically modified. Several patents report on modification of keratin fibers using enzymes for applications such as the properties enhancement of harshly treated wool textiles [10], or for hair styling and coloring under mild conditions [11-13]. The usage of protein disulphide isomerase (PDI) enzyme for incorporation of functional molecules onto keratinous substrates was previously reported by our group [14,15]. In previous hair studies samples are normally bleached with hydrogen peroxide [14,15]. Bleaching of hair [16-18] is commonly employed with the purpose of original color removal from the bulk of a fiber for coloration [19].

In vivo phosphorylation is considered an important posttranslational modification of proteins. It affects intra- and intermolecular interactions [20] and is stable under physiological conditions [21]. In the context of keratin, phosphorylation and

\footnotetext{
* Corresponding author. Fax: +351253604 429.

E-mail address: artur@deb.uminho.pt (A. Cavaco-Paulo).
}

dephosphorylation affect its interactions with other proteins [22] and the organization of keratinous filaments [23]. The essential role of keratin remodeling by phosphorylation in living systems has been demonstrated through the observations of its different mutation and mis-expression experimental models [24]. The degree of phosphorylation may vary [25], and it is assumed to be carried out by several kinases: cAMP- and $\mathrm{Ca}^{2+} /$ calmodulin-dependent kinases, protein kinase C [26]. Currently, no work on in vitro phosphorylation of keratins can be found in literature.

Adsorption is a concentration change of a given substance between the boundaries of two phases as compared with the surrounding bulk phases [27]. Underlying mechanisms of adsorption processes are usually complex because of structural and energetic heterogeneity of the surfaces that is common to a vast number of adsorbents routinely used [28]. Hence, extensive modeling is needed in many cases, in order to evaluate the adsorption mechanism pathways, to express the surface properties and capacities of adsorbents, and effectively construct the adsorption systems [29]. The heterogeneity of hair, whether physical and/or chemical, implies that the binding of applied adsorbents to its surface is expected to be more complex than that to homogeneous solid surfaces.

In the current work and for the first time keratin was phosphorylated by protein kinase A (PKA) with exogenously supplied ATP. Throughout the manuscript, the phosphorylated hair will also be referred to as a modified hair. Methylene blue (MB) adsorption/desorption studies were performed, aiming to check the characterization of the keratin modification. Acquired data were 
fit by different kinetic and thermodynamic models, and the arisen findings were discussed.

\section{Materials and methods}

\subsection{Materials}

Human virgin hair of Caucasian origin was supplied by International Hair Importers \& Products Inc., (USA) and used as provided. Methylene blue dye was of Carlo Erba Reagents (Italy). Trizma ${ }^{\circledR}$ base, $\mathrm{NaOH}, \mathrm{HCl}$, protein kinase A (Cat.nr. P5511) and Esperase ${ }^{\circledR}$ 8.0L protease (Cat.nr. P5860) were obtained from Sigma-Aldrich (Spain). All reagents were of analytical grade.

\subsection{Preparation of (phospho-) keratin samples}

Prior to phosphorylation, hair was subjected to 5 cycles of bleaching, similarly to the reported protocol [30]. During a separate cycle, $2 \mathrm{gr}$ of dry hair tresses were immersed in $200 \mathrm{~mL}$ solution containing $12 \mathrm{wt} \% \mathrm{H}_{2} \mathrm{O}_{2}$ in $0.1 \mathrm{M} \mathrm{Na}_{2} \mathrm{CO}_{3}, \mathrm{pH} 9.0$ buffer, at $50^{\circ} \mathrm{C}$ for $1.5 \mathrm{~h}$. Bleaching solution was flashed after each cycle. Subsequently, bleached hair was thoroughly rinsed with distilled water, dried and stored at room temperature at 40-45\% relative humidity. Prior to phosphorylation, the hair was pre-conditioned in PKA buffer (recipe given in [31]) for $1 \mathrm{~h}$; conditioning buffer was then replaced by a fresh one. Phosphorylation was carried out using PKA, similarly to the reported method [31]. A typical reaction of $10 \mathrm{~mL}$ total volume was constituted by 0.28 gr hair, 90 PKA units, $0.5 \mathrm{mM}$ ATP and $100 \mu \mathrm{M}$ cyclic-AMP. The reaction was terminated by three washings in ultra-pure water (one brief and the following two of 10 min each), samples were dried and stored as described previously. The non-phosphorylated hair, serving as a negative control, experienced all of the above treatments with a single exception-no kinase enzyme was added to the reaction mixture.

\subsection{Infra-red spectroscopic characterization of hair}

Diffuse Reflectance Infrared Fourier Transform (DRIFT) analysis was performed on Spectrum 100 of PerkinElmer Inc., (USA), equipped with diffuse reflectance sampling accessory. For the sampling of hair tresses, uncoated Si-C abrasive pads (Cat.nr. L1271021, PerkinElmer) were used. The hair was actually scratched by the pads, and the dust-containing samples analyzed. The background was acquired with a clean pad. Data were collected from two independent measurements, each one was done in 64 rescan mode. The scan range was taken from 450 to $4000 \mathrm{~cm}^{-1}$ with a resolution of $16 \mathrm{~cm}^{-1}$. Spectral normalization was automatically performed by the software, Spectrum v6.3.5.0176 (PerkinElmer).

\subsection{Nuclear magnetic resonance spectroscopy of hair}

NMR was performed on Bruker Avance III $400 \mathrm{MHz}$ spectrometer (USA). ${ }^{31} \mathrm{P}$ spectra were obtained at the frequency $162 \mathrm{MHz}$ with the spinning rate of $20 \mathrm{RPM} .{ }^{1} \mathrm{H}$ decoupling was performed and $64 \mathrm{~K}$ data-points collected. For each sample, 20,700-20,900 transient scans were collected. External phosphoric acid was used to express the relativity of detected chemical shifts.

Hair samples of both types (non-phosphorylated and phosphorylated) were partially degraded with Esperase ${ }^{\circledR}$ 8.0L as following. $150 \mathrm{mg}$ dry hair was incubated with $6 \mathrm{U}$ protease at $50^{\circ} \mathrm{C}$ for $1 \mathrm{~h}$. The reaction buffer was $40 \mathrm{mM}$ Tris- $\mathrm{HCl}, \mathrm{pH} 9.4$, devoid of any other salt. Proteinaceous debris were separated from the rest of solution by centrifugation and supernatant taken to NMR assay.

\subsection{Methylene blue adsorption/desorption studies}

Initially, dye stock solution was prepared, obtaining a final concentration of $2000 \mathrm{mg} \mathrm{L}^{-1}$. All the solutions of different $\mathrm{pH}$ were prepared as described elsewhere [32]. Instead of water, $50 \mathrm{mM}$ Tris- $\mathrm{HCl}$ buffer was used. Simple dye adsorption/desorption tests were performed by incubating various hair samples with MB dye, and, consequently without MB. The adsorption/desorption tests were performed in batch conditions by shaking the adsorbate at 40 $\mathrm{RPM}$ in $10 \mathrm{~mL}$ incubation solutions, at $20^{\circ} \mathrm{C}$, unless other temperature was indicated. All the adsorption experiments were performed using a constant adsorbent dosage of 1.1 , i.e., (11 mg dry hair mass $) /(10 \mathrm{~mL}$ MB dye starter solution). For desorption examinations, the dye-loaded hair was previously and gently washed in $10 \mathrm{~mL}$ ultra-pure water for $1 \mathrm{~min}$ to remove any un-adsorbed dye. Discrete MB concentrations were determined spectrophotometrically by reading the solutions against standard curves at $665 \mathrm{~nm}$.

The adsorption capacities $Q_{t}, Q_{\text {equ }}$ and $Q_{\max }\left(\mathrm{mgg}^{-1}\right)$ and the percentage removal efficiency $R(\%)$ were calculated as previously described [32,33]:

$Q=\frac{\left([\mathrm{MB}]_{\text {init }}-[\mathrm{MB}]_{\mathrm{fin}}\right) V}{m}$ and

$R=\left(\frac{\text { desorbed }}{\text { loaded }}\right) \times 100 \%$

where $[\mathrm{MB}]_{\text {init }}$ and $[\mathrm{MB}]_{\text {fin }}$ are initial and final dye concentrations $\left(\mathrm{mg} \mathrm{mL}^{-1}\right), V$ is MB solutions volume $(\mathrm{mL}), m$ is dry hair mass $(\mathrm{g})$. Desorbed and loaded are the amounts of MB dye $(\mathrm{mg})$, removed or deposited by adsorption/desorption experiments. All the assays were carried out in duplicate with double sampling at each time point; mean values were reported.

\subsection{Acquired data processing}

Data that needed fitting were exported to OriginPro software, v8.5.0 by OriginLab Corporation (USA). Linear fit was performed by using the appropriate routine with default software settings. DRIFT-derived spectra were smoothed in OriginPro software by Adjacent-Average method, without weighting. Filter window size of 15 points was used. Empiric data were fit by or substituted into several equations, presented in Table S1.

\subsection{Sample preparation for confocal microscopy, image acquisition and 3D modeling}

Separate hair shafts were embedded in epoxy cold mounting system (Cat. nr. 40200029, Stuers, UK) according to the supplier's protocol, and the system was left to cure. Obtained solid material was polished and subsequently sliced by a blade microtome machine, producing slices of $15 \mu \mathrm{m}$ thickness. The sliced straps, containing hair, were mounted on glass slides and inspected on Olympus BX61/FV1000 confocal system, operating under Olympus Fluoview v4.0 software (Olympus Corp., Japan). 635 nm wavelength diode laser, operating at $2 \%$ of power, was used to excite the dye; emission was collected through BA $655-755 \mathrm{~nm}$ band-pass filter. PLAPONSC $60 \times$ oil objective with numerical aperture of 1.4 was utilized. During the image acquisition, depending on the fluorescent output, the High Voltage and PMT Gain parameters were manually adjusted until the appearance of first sings of saturation or a noisy background. Constant Offset parameter of 10 was used.

Acquired 3-dimentional (3D) images were loaded into Imaris ${ }^{\circledR}$ v.7.0.0 software (Bitplane AG, Switzerland) and the corresponding 3D models were built. For the sites of major dye affinity, background subtraction with thresholding of $1.035 \mu \mathrm{m}$ was performed, the rest of the building algorhytm parameters were set to automatic. For 
A.

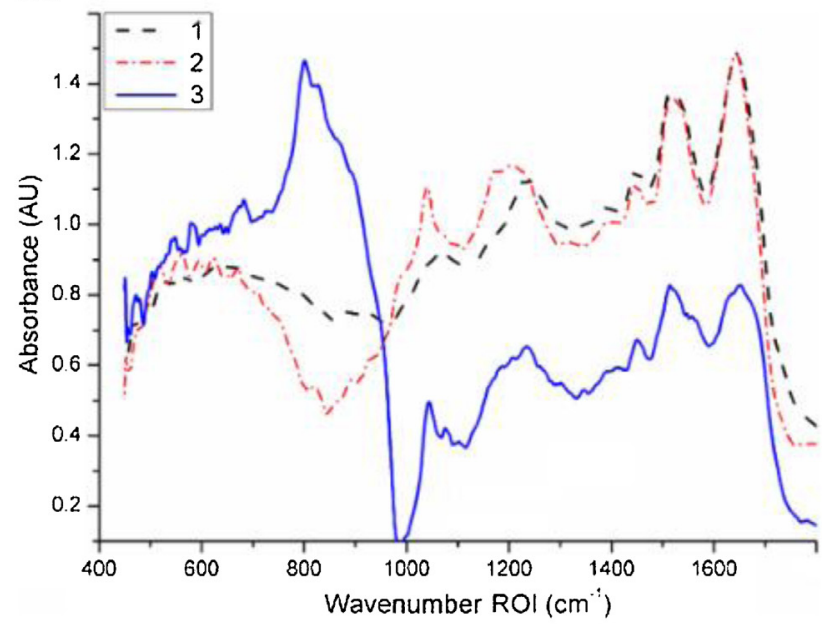

B.

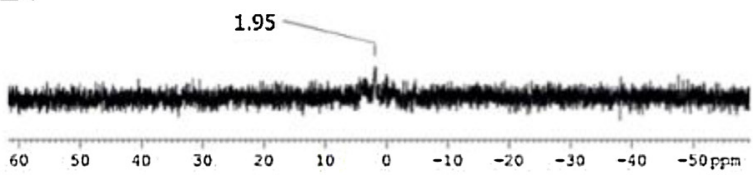

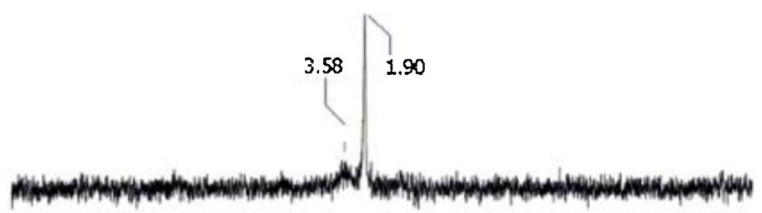

$\begin{array}{llllllllllll}30 & 25 & 20 & 15 & 10 & 5 & 0 & -5 & -10 & -15 & -20 & -25 \mathrm{ppr}\end{array}$

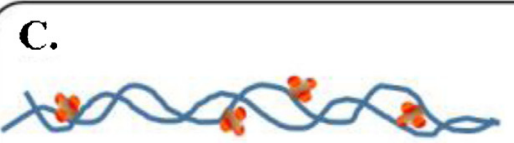

Phospho-keratin filament assembly

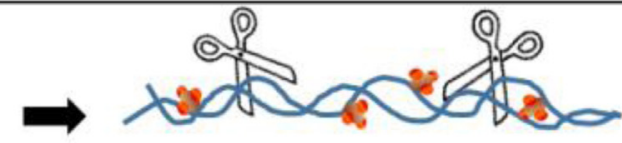

Protease-mediated degradation

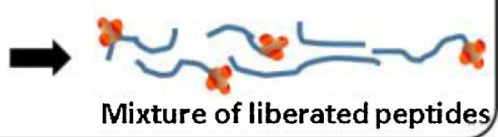

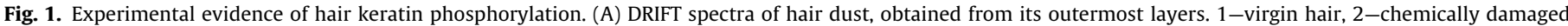

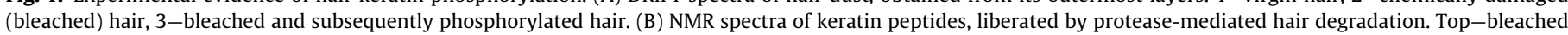
hair only, bottom-bleached and subsequently phosphorylated hair. (C) Schematic representation of protocol, employed for B. $\mathcal{Q}$ designates a phospho-group.

the bulk hair shaft volume visualization, automatic smoothing was performed.

\section{Results}

\subsection{Evidences to the phosphorylation of hair keratin}

To confirm the enzymatically-driven phosphate incorporation in chemically damaged hair, two methods were employed. Since regular ATR-FTIR was not able to detect phosphate-related vibrational peaks on modified keratin during preliminary examinations made on Merino wool (Fig. S1), DRIFT was performed. Fig. 1A depicts IR spectra of differently treated hair in the region of interest (ROI) of $1800-400 \mathrm{~cm}^{-1}$. The common peaks of Amide I, II and III $\left(1650,1540\right.$ and $1200 \mathrm{~cm}^{-1}$, respectively) [34] are the first to be mentioned. Two additional bands [34], also shared by all hair types, are the somewhat subtle peak from aromatic and imidazole rings of Trp, His and Pro $\left(1450 \mathrm{~cm}^{-1}\right)$; and the sharply appearing Thr/Ser C-O stretching vibrations $\left(1050 \mathrm{~cm}^{-1}\right)$. Interestingly, the $\mathrm{C}-\mathrm{O}$ vibration was hardly observed for the virgin hair, what may signify that its intact outer-layers together with lipid coating of 18methyleicosanoic acid [35] (18-MEA) shield inner structures from IR irradiation. Finally, a bimodal peak at $830 / 800 \mathrm{~cm}^{-1}$ is observed solely for the phosphorylated hair. In-phase $\mathrm{P}-\mathrm{O}-\mathrm{C}$ stretching vibrations can produce such a peak ([36] or refer to triethyl phosphate IR spectrum available online). The abnormal inverted peak at $980 \mathrm{~cm}^{-1}$ is most likely an artifact of Restrahlen reflection of the abraded hair samples [37].

To further confirm the existence of phosphate group introduced into keratin, NMR of differently treated and degraded hair shafts was performed (Fig. 1C). From Fig. 1B (top) it is seen that non-phosphorylated hair peptides showed only a basal phosphaterelated peak, whilst kinase-reacted hair indicated a pronounced peak. The very weak phospho-peak of non-phosphorylated keratin may be attributed to some basal level of phosphorylation, naturally present [38]. Taking into account the number of scans, required for the peaks in Fig. 1B to appear (Section 3.4) and the sensitivity of the equipment (Fig. S2), the phosphate found within the fibers is considered to be at $\mu$-molar amounts.

\subsection{Preliminary adsorption studies. Calculation of hair adsorption capacity}

The estimation of MB starting concentrations were done to calculate maximal adsorption capacity $\left(Q_{\max }\right)$ values. The results for different adsorption capacity $\left(Q_{t}\right)$ values are depicted in Fig. 2. For both hair treatments, $Q_{t}$ increases as the MB concentration in starter solution $\left([\mathrm{MB}]_{\text {init }}\right.$ ) increases, until an equilibrium, seen as graphs' plateau, is reached. It is evident that phospho-hair adsorbs more dye, than the non-phospho-hair. Moreover, $[\mathrm{MB}]_{\text {init }}$ for the phosphorylated hair is $0.57 \mathrm{mg} \mathrm{mL}^{-1}$. This value was used in all later experiments.

\subsection{Kinetic, modeling and mechanistic aspects of $M B$ adsorption}

Once the best $[\mathrm{MB}]_{\text {init }}$ was known, it was possible to conduct extended kinetic investigations of the dye binding. Hair samples were incubated at $20^{\circ} \mathrm{C}$ for $24 \mathrm{~h}$ and adsorption progress frequently monitored during the first $3.5 \mathrm{~h}$ of the experiment. The last time point collected was at 24th hour. Experimental outcome is presented in Fig. 3. Again it is clear that keratin with additionally incorporated phosphate demonstrates better dye uptake.

To gain additional insights on the dye-hair interaction, several models were applied to empirically acquired data. Namely: the pseudo-first order (PFO), pseudo-second order (PSO) and intraparticle diffusion models. Empirical data points with matching fitted curves are presented in Fig. S3, calculated kinetic values given in Table 1 and the corresponding equations appear in Table S1. Based on the similarity of $Q_{\max }$ and $Q_{\text {equ }}$, as well as on the values of adjusted coefficient of determination $\bar{R}^{2}$ it can be concluded that the PSO model describes dye uptake kinetics in the best way, meaning that the uptake is dependent on both dye concentration and avail- 


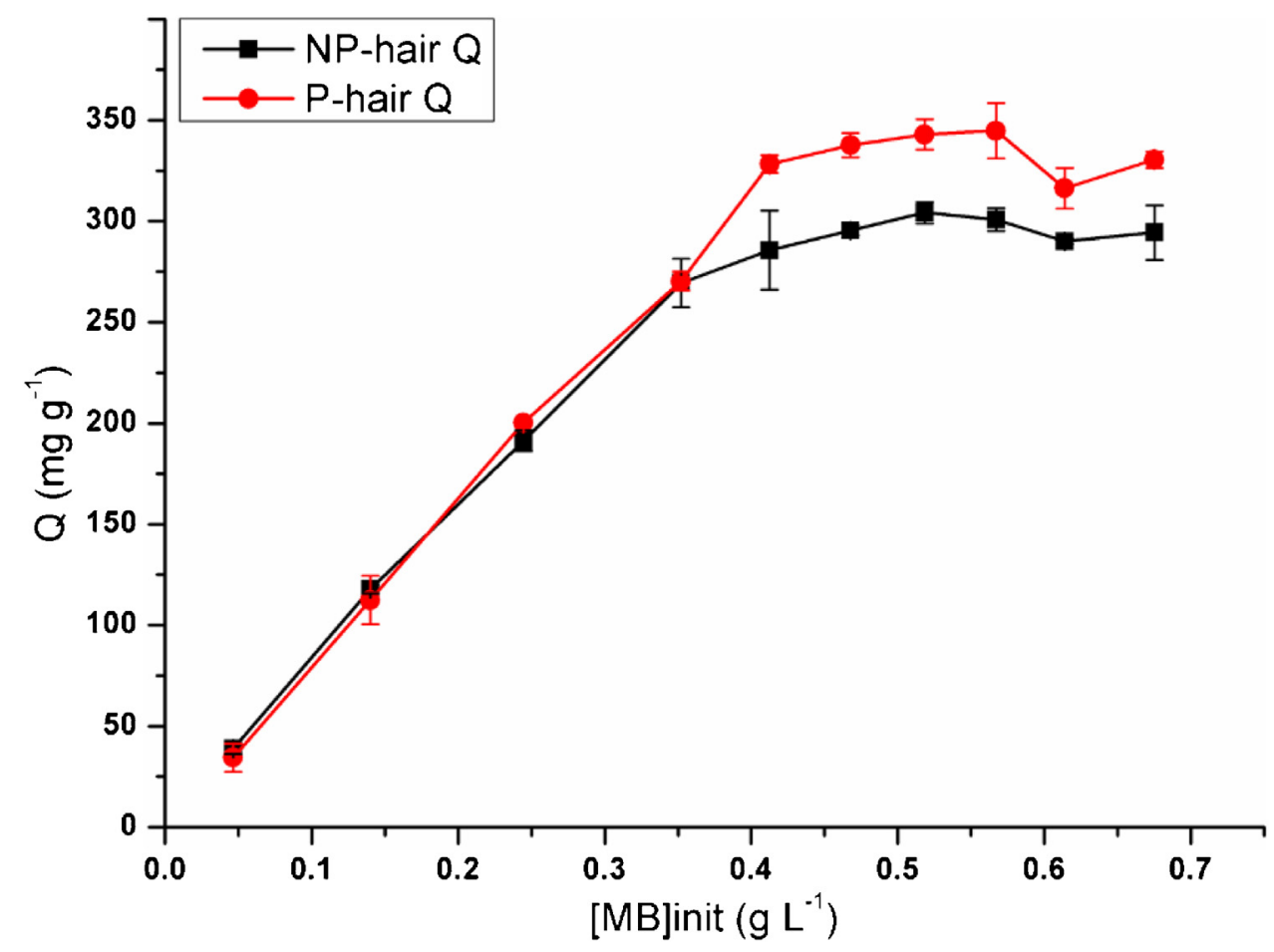

Fig. 2. Determination of maximal adsorption capacity $\left(Q_{\max }\right)$ for the two types of hair samples. Hair was incubated in MB solutions of variable initial concentration, $[M B]_{\text {init }}$, and $Q_{\max }$ was assessed as described. NP- and P-designate the non-modified or enzymatically modified hair, respectively.

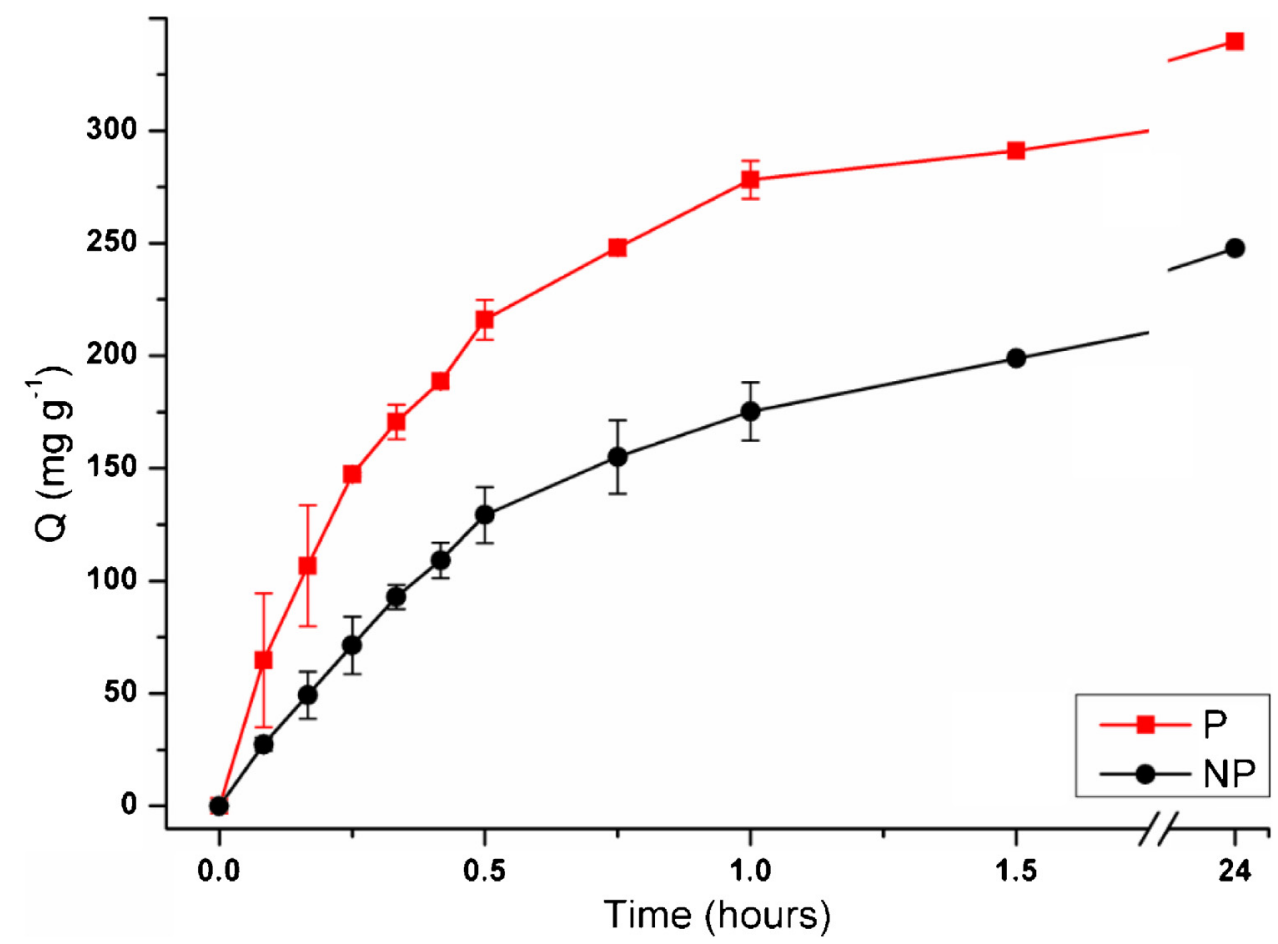

Fig. 3. Time-lapse examination of MB adsorption onto differently treated hair. High-resolution representation of the first $1.5 \mathrm{~h}$ of incubation. NP and $\mathrm{P}$ designate the non-modified or enzymatically modified hair.

ability of binding sites in the adsorbent. Moreover, the values of constant $C$ indicate additional factors [39], such as boundary layer thickness and boundary layer diffusion that also govern the masstransfer of MB from solution to the hair adsorbent. The current findings on adsorption rate and on additional phenomena, arising from the intra-particle model, corroborate the previously reported conclusions for adsorption tests in various systems [32,33,39,40].

Although the reaction of adsorption is commonly characterized by Langmuir and Freundlich isotherms, other isotherm models may be applied, depending on the need. As such, Dubinin-Radushkevich 
Table 1

Estimated kinetic parameters of MB dye adsorption on different hair types.

\begin{tabular}{|c|c|c|c|c|}
\hline \multirow[t]{2}{*}{ Model applied } & \multirow[t]{2}{*}{ Hair types } & \multicolumn{2}{|c|}{ Kinetic parameters, calculated from modeling } & \multirow[t]{2}{*}{$\bar{R}^{2}$} \\
\hline & & $Q_{\text {equ }}\left(\mathrm{mgg}^{-1}\right)$ & $k_{1}\left(\min ^{-1}\right)$ & \\
\hline \multirow[t]{4}{*}{ Pseudo-first order } & $\mathrm{P}$ & 238.979 & 0.0159 & 0.9638 \\
\hline & NP & 206.262 & 0.0142 & 0.9844 \\
\hline & & \multicolumn{2}{|c|}{ Kinetic parameters, calculated from modeling } & $\bar{R}^{2}$ \\
\hline & & $Q_{\text {equ }}\left(\mathrm{mgg}^{-1}\right)$ & $k_{2}\left(\mathrm{~g} \mathrm{mg}^{-1} \mathrm{~min}^{-1}\right)$ & \\
\hline \multirow[t]{4}{*}{ Pseudo-second order } & $\mathrm{P}$ & 355.871 & $1.504 \times 10^{-4}$ & 0.9924 \\
\hline & NP & 273.224 & $1.067 \times 10^{-4}$ & 0.9747 \\
\hline & & \multicolumn{2}{|c|}{ Kinetic parameters, calculated from modeling } & $\bar{R}^{2}$ \\
\hline & & $C\left(\mathrm{mg} \mathrm{g}^{-1}\right)$ & $k_{\mathrm{i}}\left(\mathrm{g} \mathrm{mg}^{-1} \mathrm{~min}^{-1 / 2}\right)$ & \\
\hline \multirow[t]{2}{*}{ Intra-particle diffusion } & $\mathrm{P}$ & 18.654 & 20.715 & 0.8746 \\
\hline & NP & 10.340 & 16.573 & 0.9359 \\
\hline
\end{tabular}

NP and P designate the non-modified or enzymatically modified hair.

Table 2

Parameters of the isotherms, applied on MB dye adsorption curves for different hair types.

\begin{tabular}{|c|c|c|c|c|}
\hline \multirow[t]{2}{*}{ Model applied } & \multirow[t]{2}{*}{ Hair type } & \multicolumn{2}{|c|}{ Types of isothermal parameters and their values } & \multirow[t]{2}{*}{$\bar{R}^{2}$} \\
\hline & & $Q_{\max }\left(\mathrm{mgg}^{-1}\right)$ & $K_{\mathrm{L}}\left(\mathrm{L} \mathrm{mg}^{-1}\right)$ & \\
\hline \multirow[t]{4}{*}{ Langmuir } & NP & 322.580 & $49.301 \times 10^{3}$ & 0.9868 \\
\hline & $\mathrm{P}$ & 374.531 & $46.675 \times 10^{3}$ & 0.9647 \\
\hline & & \multicolumn{2}{|c|}{ Types of isothermal parameters and their values } & $\bar{R}^{2}$ \\
\hline & & $\bar{n}$ & $k_{\mathrm{f}}\left(\mathrm{mgg}^{-1}\right)\left(\mathrm{L} \mathrm{mg}^{-1}\right)^{1 / n}$ & \\
\hline \multirow[t]{4}{*}{ Freundlich } & NP & 4.041 & 2275.602 & 0.716 \\
\hline & $\mathrm{P}$ & 3.698 & 3387.677 & 0.8296 \\
\hline & & \multicolumn{2}{|c|}{ Types of isothermal parameters and their values } & $\bar{R}^{2}$ \\
\hline & & $Q_{\max }\left(\mathrm{mg} \mathrm{g}^{-1}\right)$ & $E\left(\mathrm{~kJ} \mathrm{~mol}^{-1}\right)$ & \\
\hline \multirow[t]{2}{*}{ Dubinin-Radushkevich } & NP & 729.894 & 14.974 & 0.7669 \\
\hline & $P$ & 976.72 & 14.315 & 0.8506 \\
\hline
\end{tabular}

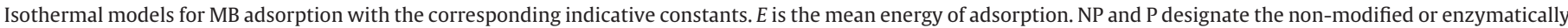
modified hair.

(D-R) isotherm serves the answer for qualitative evaluation of adsorption mechanism with a particular energy distribution onto a heterogeneous, porous surface. In the current work all of the aforementioned isotherm models were used [41]; their linearized equations are given in Table S1. Langmuir model presumes that adsorption occurs at specific and homogenous sites within the adsorbent, with the adsorbate forming a monolayer that covers the adsorbent; Freundlich model assumes that some heterogeneous adsorption surface exists, with sites of different energies of adsorption and non-equal availability. The data, obtained from $Q_{\max }$ determination experiments, were fitted by the chosen models. Resulting fits are presented in Fig. S4 and the calculated parameters, corresponding to each isotherm model are given as Table 2 . It can be seen that Langmuir isotherm describes best the dye adsorption, similarly to previous works [32,33], however this is not the case of dimethylpabamidopropyl laurdimonium tosylate (DDABDT) adsorption on delipided human hair, where the Freundlich model fits the observed process in a better way [40]. In this case the molecular structures of both adsorbate (a long-chain alkylated quaternary ammonium compound) and a hair adsorbent (virtually intact fibrous framework, except for 18-MEA removal) reflect on the binding mechanisms that differ from other systems mentioned. Freundlich model was also found to be the most appropriate for description of MB removal from aqueous solution by silkworm exuviae [42]. The degree of surface heterogeneity $1 / n$, known from the slope of a curve by plotting $\ln Q_{\text {equ }}$ versus $\ln [\mathrm{MB}]_{\text {equ }}$ indicates more heterogeneous surface if inequality $1 / n$ « 1 holds and the factor $1 / n$ decreases [43]. Therefore, it is worth noticing that the currently reported $1 / n\left(1 / n_{\mathrm{NPhair}}=0.2474\right.$ and $\left.1 / n_{\text {Phair }}=0.2704\right)$ is roughly twice smaller than the one presented previously [42] (for the closest temperature available: $1 / n=0.5370$ ). Thus, the heterogeneity of chemically damaged hair is higher than that of silkworm exuviae, though phosphorylation seems to decrease this property.

By using Langmuir model it can be assessed whether a given adsorption system is favorable or not. For that, a dimensionless constant, $R_{\mathrm{L}}$, is defined as following:

$R_{\mathrm{L}}=\frac{1}{\left(1+K_{\mathrm{L}}[\mathrm{MB}]_{\text {init }}\right)}$

$R_{\mathrm{L}}$ indicates irreversible $\left(R_{\mathrm{L}}=0\right)$, favorable $\left(0<R_{\mathrm{L}}<1\right)$, linear $\left(R_{\mathrm{L}}=1\right)$ or unfavorable $\left(R_{\mathrm{L}}>1\right)$ adsorption. Both modified and non-modified hair exhibited $R_{\mathrm{L}}$ values in the range: $3.00 \times 10^{-5}<R_{\mathrm{L}}<4.46 \times 10^{-4}$ (Fig. S5), thus indicating a favorable process.

A similar conclusion can be drawn from Freundlich modelderived parameter $n$. $n$ falling within the value range of 2-10 represents good, 1-2 moderately difficult, and less than 1 poor sorption [33]; therefore the values appearing in Table 3 point on a favorable sorption. 
Table 3

Thermodynamic parameters of the MB dye adsorption onto different hair types.

\begin{tabular}{|c|c|c|c|c|c|c|c|}
\hline \multirow[t]{2}{*}{ Hair type and [MB] } & \multicolumn{3}{|c|}{ van't Hoff equation-derived } & \multicolumn{4}{|c|}{$\Delta G$ at chosen temperature $\left(\mathrm{kJ} \mathrm{mol}^{-1}\right)$} \\
\hline & $\Delta H\left(\mathrm{~kJ} \mathrm{~mol}^{-1}\right)$ & $\Delta S\left(\mathrm{~J} \mathrm{~mol}^{-1}\right)$ & $R^{2}$ & $20^{\circ} \mathrm{C}$ & $30^{\circ} \mathrm{C}$ & $40^{\circ} \mathrm{C}$ & $50^{\circ} \mathrm{C}$ \\
\hline $\mathrm{P}$ & -29.106 & 19.991 & 0.9882 & -34.990 & -35.196 & -35.204 & -35.663 \\
\hline $\mathrm{NP}$ & -20.347 & 43.803 & 0.9573 & -33.306 & -33.463 & -33.967 & -34.620 \\
\hline
\end{tabular}

Calculated values of enthalpy $\Delta H$, entropy $\Delta S$ and Gibbs free energy $\Delta G$. NP and P designate the non-modified or enzymatically modified hair.

\subsection{Thermodynamic aspects of $M B$ adsorption and desorption experiments}

To gain additional important insights into dye-hair interactions Dubinin-Radushkevich (D-R) isotherm model was used. Although being not the best model to describe our binding system, D-R isotherm offers assessment of adsorption energy by the calculation of related constant $\beta$. The constant is presented in the linearized equation of this isotherm (Table S1). It can be obtained from the slope of a curve by plotting $\ln Q_{\text {equ }}$ versus $\varepsilon^{2}$. In turn, $\varepsilon$ is equal to $R T \ln \left(1+[\mathrm{MB}]_{\text {equ }}^{-1}\right)$. So that $\beta$ enables the researcher to calculate the mean energy of adsorption $E$ as defined [44]: $E=(2 \beta)^{-2.5}$. Having $\beta_{\mathrm{NP} \text { hair }}=0.00223$ and $\beta_{\mathrm{P} \text { hair }}=0.00244 \mathrm{~mol}^{2} \mathrm{~kJ}^{-2}$, the resulting energy is obtained in the range of $14<E<15 \mathrm{~kJ} \mathrm{~mol}^{-1}$ for both hair types, indicating an ion-exchange mechanism of dye uptake [45]. In our particular case, energy was needed to transfer the dye ions from the solution to the surface of two different adsorbents, however for the phosphorylated hair this energy uptake was somewhat lower, which reflects the elevated favorability of phosphorylated hair as a material for MB adsorption.

In parallel, the changes in adsorption enthalpy $\Delta H$, entropy $\Delta S$ and Gibbs free energy $\Delta G$ were calculated using the corresponding equations from Table $\mathrm{S} 1 . \Delta H, \Delta S$ and $\Delta G$ values are presented in Table 3. It can be seen that dye adsorption was exothermic in nature and during this process the entropy slightly increased. The increase in entropy was more prominent for the non-modified hair. Since negative $\Delta G$ values were obtained for all conditions examined, the adsorbate uptake was thermodynamically favorable. Owing to the exothermic nature of MB uptake, a trend of decreasing $Q$ with incubation temperature augmentation was observed (Fig. 4A).

The thermodynamic behavior of our system can be viewed in the context of similar studies. Two works report on MB uptake as an exothermic process. One study estimates $E$ of similar magnitude [32], the other describes spontaneous adsorption of the dye accompanied by significant decrease in $\Delta S$ [46]. The adsorption of hematoxylin (chemically similar to $\mathrm{MB}$ ) onto yak hair was reported as an exothermic, spontaneous and with entropy increase for temperatures of $30^{\circ} \mathrm{C}$ and above [47]. Other systems for MB removal from industrial effluents are generally endothermic, spontaneous and cause $\Delta S$ elevation during the dye uptake [42,48-50].

The ultimate factor to be elucidated was the $\mathrm{pH}$ variability of the MB incubation solution. In our experiments higher values of $Q$ were observed with increased $\mathrm{pH}$ (Fig. 4B). As a cationic dye, MB tends to bind more easily to a negatively charged surface, whose electrostatic properties, in turn, depend on both $\mathrm{pH}$ and phosphorylation. Non-modified material showed mildly rising adsorption trend-line as $\mathrm{pH}$ incremented from 4.0 to 7.0 , while the modified material demonstrated constantly increased adsorption. After the neutral $\mathrm{pH}$ is passed $Q$ rises abruptly for the non-modified adsorbent. The tendency of $Q$ augmentation with rising $\mathrm{pH}$ is in line with earlier recorded data of $\mathrm{MB}$ adsorption onto several biosorbents $([32,42,46,48]$ or Table 4$)$.

Since the main scope of the current work was elucidation of mechanisms governing the MB uptake by the human hair-based adsorbent, only qualitative studies for the dye desorption were performed.
To do time-lapse examination of desorption process MB-loaded samples were incubated at $20^{\circ} \mathrm{C}$ for $24 \mathrm{~h}$ and adsorption progress frequently monitored during the first $3.5 \mathrm{~h}$. Resulting removal efficiencies $R$ for various conditions are shown in Fig. 5. As opposed to the tendency of $Q$ to grow with phosphorylation, $R$ increases with its absence. To NP condition, MB that is bound non-specifically to the hair shafts is thought to be the most contributing factor for higher $R$ values. It makes sense that the modified adsorbent P-possesses higher affinity for the dye, hence its calculated $R$ is smaller.

Temperature- and $\mathrm{pH}$ - dependent examinations of MB desorption revealed that it is an endothermic process and disfavored at basic $\mathrm{pH}$ values (Fig. 6). The first observation (temperature dependence) contradicts the previously reported conclusion made for keratin-derived nanofibrous membranes [32], however it concords with the study done on sheep wool as adsorbent [46]. Thus the result currently obtained is a plausible one, since our system physically resembles more the system of Khan et al. [46], i.e. wool fibers and not electrospun membranes. The second observation ( $\mathrm{pH}$ dependence) contradicts the previously reported one as well [32], probably because of the higher amount of negatively charged groups per se and their further enhancement by a rising $\mathrm{pH}$.

\section{5. $3 D$ visualization of the hair-bound dye}

Finally, we obtained the images of differently bound dye onto various adsorbents, by confocal microscopy. For that, modified and non-modified dried hair shafts were incubated for $1 \mathrm{~min}$ in $0.025 \mathrm{~g} \mathrm{~L}^{-1} \mathrm{MB}$-containing buffer, fixed with epoxy resin and further processed (Section 3.7). The short immersion time allowed for the dye binding preferably to the sites of highest affinity (whether phospho-sites or any others of similar binding capacity). Resulting images are presented in Fig. 7. It can be seen that the modified hair was able to adsorb more dye. Moreover, the calculated volumetric ratios for both hair types: $V_{\text {dye-bound hair }} / V_{\text {total hair }}$, reported by Imaris ${ }^{\circledR}$ program, are 0.0225 and 0.0317 for a non-phosphorylated and phosphorylated material, respectively. These values indicate a $29.1 \%$ increase in the specific dye binding sites as a result of phosphorylation.

\section{Discussion}

The current work represents, for the first time, a successful attempt to enzymatically phosphorylate hair keratin. It was previously shown by others [51] and by our group [31,52] that fibrous materials can be enzymatically modified by protein kinase A. Different physico-chemical properties could be tailored by the attachment of incoming phospho-group, such as hydrophobicity and conformational changes in fibrous materials. During their biogenesis, keratinous fibers undergo post-translational modifications by endogenous enzymes [38]. Thus, it was a valuable question to ask if the in vitro phosphorylation of bleached keratin is doable. Moreover, enzymatically-driven reactions constitute an attractive and relatively novel aspect, applying to the "green chemistry" approach.

Phosphorylation of hair and its subsequent detection was a somewhat challenging task, since the levels of phosphate incorporation onto keratin are considered to be low. The main obstacle 
A.

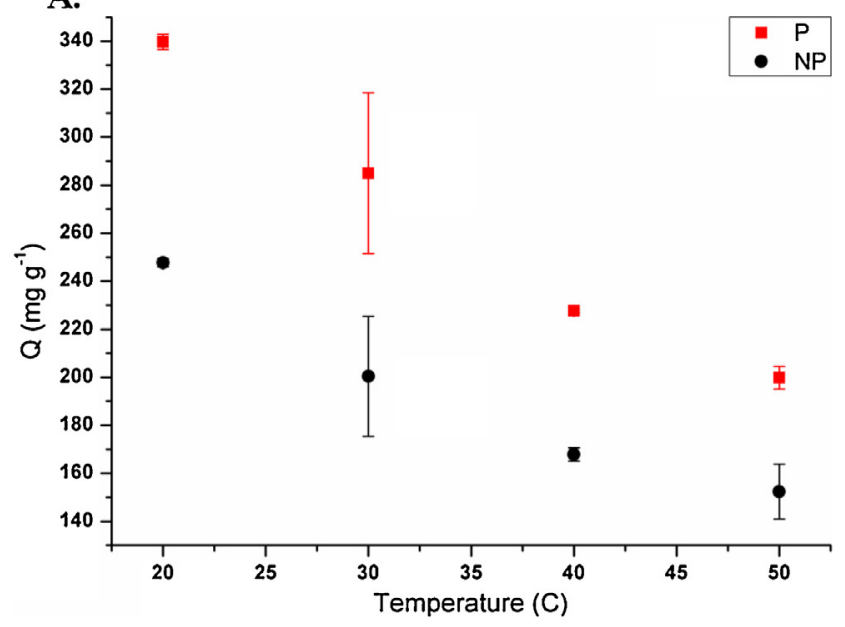

B.

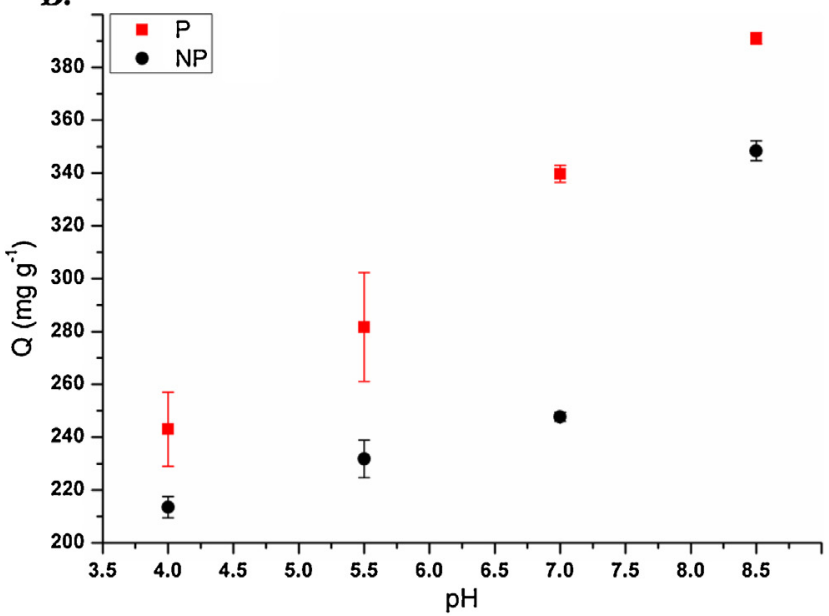

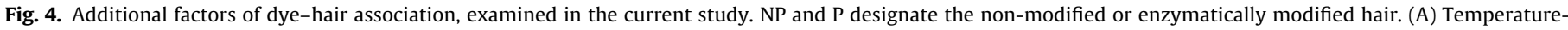
dependent adsorption. (B) pH-dependent adsorption.

\section{Table 4}

Comparative list of kinetic and thermodynamic parameters of various ionic adsorbates.

\begin{tabular}{|c|c|c|c|}
\hline $\begin{array}{l}\text { Experiment } \\
\text { Adsorbate: MB Adsorbent: NPHK }\end{array}$ & \multicolumn{2}{|c|}{ Applied models and their outcomes } & $\begin{array}{l}\text { Refs. } \\
\mathrm{g}\end{array}$ \\
\hline Adsorbate: MB Adsorbent: NPHK & $\begin{array}{l}\text { PFO } \\
\text { PSO }^{\mathrm{f}} \\
\text { Langmuir } \\
\text { Freundlich } \\
\text { Thermod. }\end{array}$ & $\begin{array}{l}Q_{\text {equ }}=206.262, k_{1}=0.0142, \bar{R}^{2}=0.9844 \\
Q_{\text {equ }}=273.224, k_{2}=1.067 \times 10^{-4}, \bar{R}^{2}=0.9747 \\
Q_{\max }=322.580, K_{\mathrm{L}}=49.301 \times 10^{3}, \bar{R}^{2}=0.9868 \\
n=4.041, k_{f}=2275.602, \bar{R}^{2}=0.716 \\
\Delta H=-20.347, \Delta S=0.0438, \Delta G=-33.306, \bar{R}^{2}=0.9573\end{array}$ & g \\
\hline Adsorbate: MB Adsorbent: NFKM & $\begin{array}{l}\text { PFO }^{\mathrm{a}} \\
\text { PSO }^{\mathrm{a}, \mathrm{f}} \\
\text { Langmuir }^{\mathrm{f}} \\
\text { Freundlich }\end{array}$ & $\begin{array}{l}Q_{\text {equ }}=24.8, k_{1}=0.0136, R^{2}=0.9092 \\
Q_{\text {equ }}=47.6, k_{2}=0.00138, R^{2}=0.9991 \\
Q_{\max }=167, K_{\mathrm{L}}=0.385, R^{2}=0.9927 \\
n=4.7, k_{f}=62.54, R^{2}=0.8080\end{array}$ & {$[32]$} \\
\hline Adsorbate: MB Adsorbent: SE & $\begin{array}{l}\text { PFO }^{\mathrm{a}, \mathrm{f}} \\
\text { PSO }^{\mathrm{a}} \\
\text { Langmuir }^{\mathrm{b}} \\
\text { Freundlich }^{\mathrm{b}, \mathrm{f}} \\
\text { Thermod. }^{\mathrm{b}}\end{array}$ & $\begin{array}{l}Q_{\text {equ }}=4.6816, k_{1}=0.0160, R^{2}=0.9320 \\
Q_{\text {equ }}=8.969, k_{2}=0.01006, R^{2}=0.9987 \\
Q_{\max }=25.53, K_{\mathrm{L}}=0.0547, R^{2}=0.9916 \\
n=1.862, k_{f}=2.887, R^{2}=0.9940 \\
\Delta H=34.751, \Delta S=0.1966, \Delta G=-24.870\end{array}$ & {$[42]$} \\
\hline Adsorbate: MB Adsorbent: SWK & $\begin{array}{l}\text { Langmuir } \\
\text { Freundlich } \\
\text { Thermod. }^{\mathrm{d}}\end{array}$ & $\begin{array}{l}Q_{\max }=0.0196^{c}, K_{\mathrm{L}}=0.036 \\
n=6.127, k_{f}=0.984 \\
\Delta H=-3.549, \Delta S=-0.305, \Delta G=-6.560\end{array}$ & {$[46]$} \\
\hline Adsorbate: HMTX Adsorbent: YWK & $\begin{array}{l}\text { PSO }^{\mathrm{b}} \\
\text { Freundlich }^{\mathrm{b}, \mathrm{f}} \\
\text { Thermod. }^{\mathrm{a}, \mathrm{b}}\end{array}$ & $\begin{array}{l}Q_{\text {equ }}=22.12, k_{2}=0.0019, R^{2}=0.996 \\
n=1.782, k_{f}=0.374, R^{2}=0.998 \\
\Delta H=-0.1034, \Delta S=0.0160, \Delta G=-5.125\end{array}$ & {$[47]$} \\
\hline Adsorbate: MB Adsorbent: CLL & $\begin{array}{l}\text { Langmuir }^{\mathrm{e}, \mathrm{f}} \\
\text { Freundlich }^{\mathrm{e}} \\
\text { Thermod. }^{\mathrm{e}}\end{array}$ & $\begin{array}{l}Q_{\max }=95.238, K_{\mathrm{L}}=0.0886, R^{2}=0.9951 \\
n=1.469, k_{f}=8.9516, R^{2}=0.9856 \\
\Delta H=21.196, \Delta S=0.1585, \Delta G=-23.163\end{array}$ & {$[48]$} \\
\hline Adsorbate: MB Adsorbent: PS & $\begin{array}{l}\text { PFO } \\
\text { PSO }^{f} \\
\text { Langmuir }^{\mathrm{d}} \\
\text { Freundlich }^{\mathrm{d}, \mathrm{f}} \\
\text { Thermod. }^{\mathrm{d}}\end{array}$ & $\begin{array}{l}Q_{\text {equ }}=71.68, k_{1}=0.0101, R^{2}=0.9612 \\
Q_{\text {equ }}=83.33, k_{2}=1.44 \times 10^{-4}, R^{2}=0.9998 \\
Q_{\max }=303.03, K_{\mathrm{L}}=0.00408, R^{2}=0.9809 \\
n=1.326, k_{f}=2.47, \bar{R}^{2}=0.9987 \\
\Delta H=8.58, \Delta S=0.0316, \Delta G=-0.69, R^{2}=0.9982\end{array}$ & [49] \\
\hline
\end{tabular}

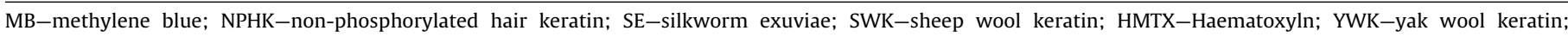
CLL-Cellolignin; PS-parsley stalks; PFO-pseudo-first order; PSO-pseudo-second order; Thermod.-thermodynamic modeling.

All the thermodynamic parameters are presented in the units of $\left(\mathrm{kJ}-\mathrm{mol}^{-1}\right)$, the rest of data bares the same units as in the previous tables.

a Presented are the data, corresponding to the lowest encountered adsorbate concentration.

b Presented are the data, corresponding to the minimal encountered temperature of incubation solutions, of $30^{\circ} \mathrm{C}$.

c Original datum presented in the units of $\left(\mathrm{mol}_{-} \mathrm{gr}^{-1}\right)$.

d Presented are the data, corresponding to the minimal encountered temperature of incubation solutions, of $20^{\circ} \mathrm{C}$.

e Presented are the data, corresponding to the temperature of incubation solutions, of $25^{\circ} \mathrm{C}$.

f Corresponds to the best-fitting model.

$\mathrm{g}$ Designates the current work.

is the low availability of amino acid residues, suitable for phosphorylation by PKA. Of all residues, constituting different keratin polypeptide chains and that could undergo phosphorylation (Ser,
Tyr, Thr), only Ser and Thr side residues are suitable substrates of PKA [53]. The enzymatic reaction, however, cannot proceed on intact hair fiber, it needs to be profoundly bleached. In the 


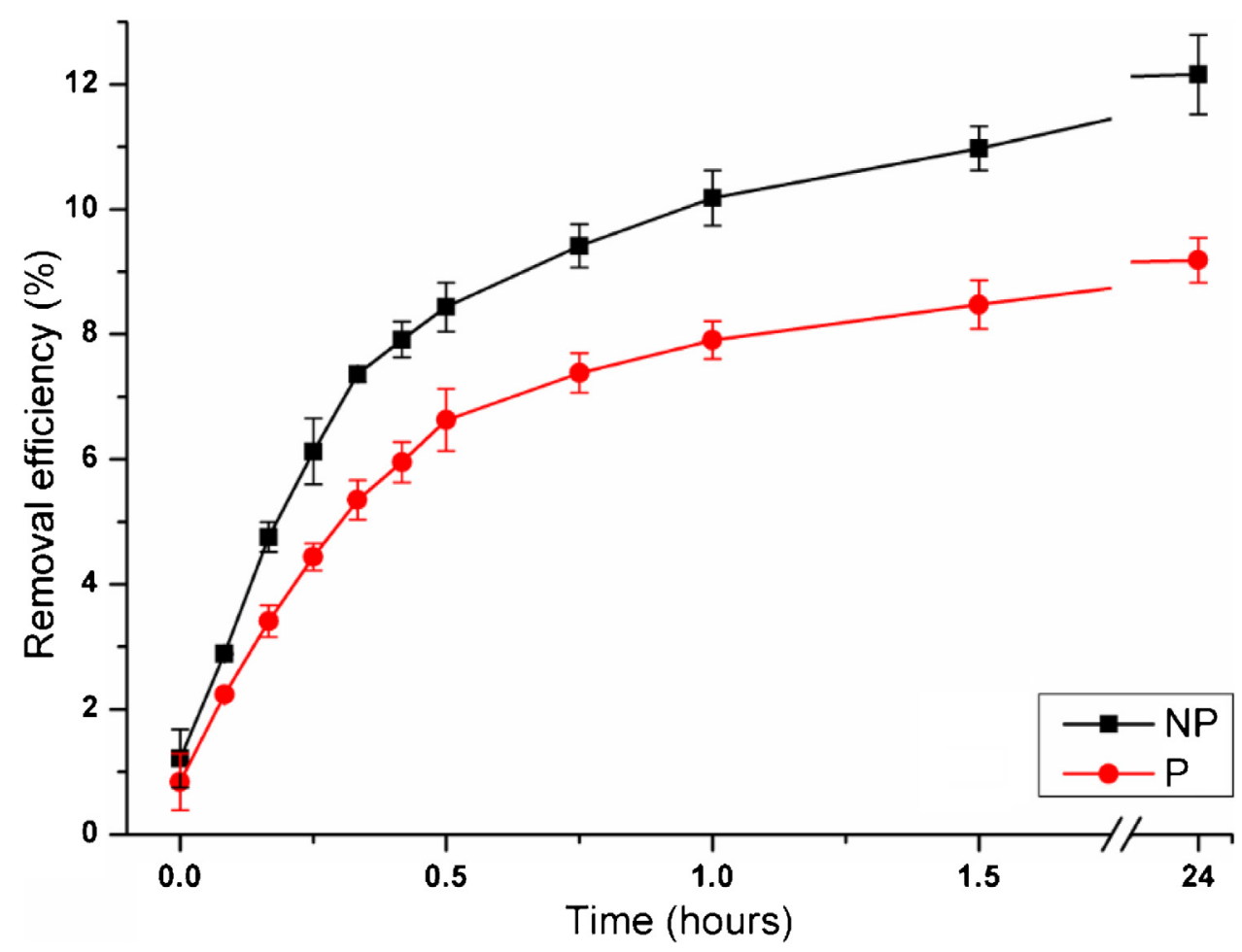

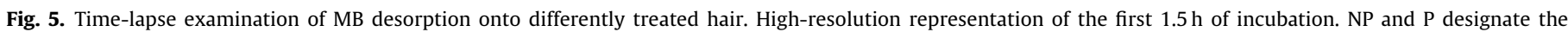
non-modified or enzymatically modified hair.
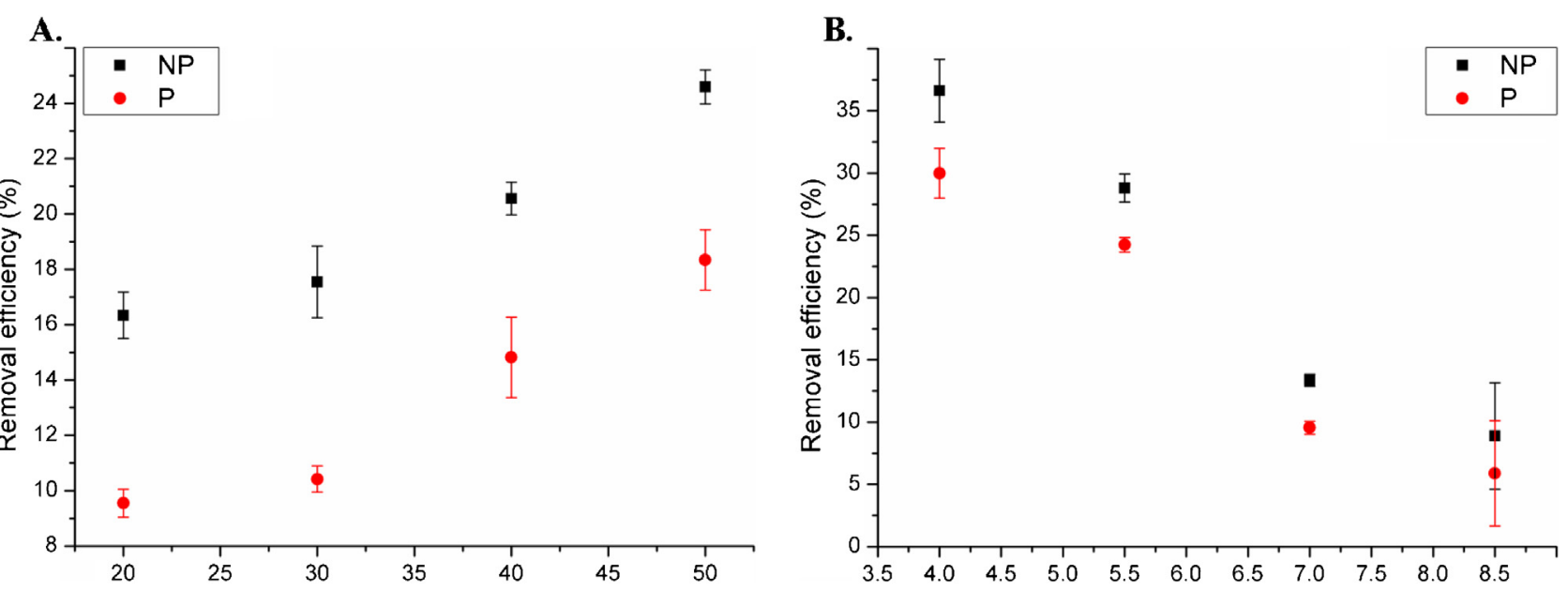

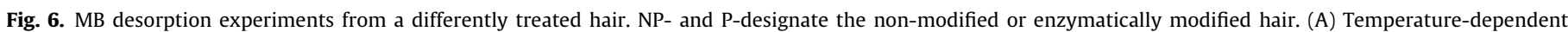
desorption. (B) pH-dependent desorption.

current work, $\approx 7 \%$ of dry hair mass was lost due to the bleaching. The damage caused by the bleaching can be roughly divided into two categories: surface damage to the cuticle and structural damage to the bulk fiber. After the bleaching process severe cuticle perforations, breaking and lifting of cuticular scales, coupled to decreased crosslink density of the hair cortex were previously reported [54,55]. Several amino acids: cystine, Lys, Arg, Pro and Thr are oxidized [56]; leaving merely Ser suitable for PKA action. As Ser constitutes $\approx 11.6 \%$ of total amino acids in $\mu \mathrm{molg}^{-1}$ of a dry and chemically intact Caucasian hair [57], one should also consider the condition whether this Ser is a part of enzyme recognition sequence or not. All of the above statements lead to conclusion that the phosphorylation extent is quite low. Fig. S1 supports that notion, although the wool material presented there underwent only delipidation, whilst our hair samples underwent both delipidation and bleaching. Final outcome is that PKA recognition sequence and general accession factors of enzyme toward a substrate (steric hindrance) probably play a pivotal role in limiting the phosphorylation extent.

ATR-FTIR and DRIFT techniques use different optical phenomena, respectively specular and diffuse reflection. DRIFT is particularly useful in the investigations of powdered and diluted (or physically discontinuous) samples [58]. As such, for the modified hair it was possible to obtain phosphate-specific signal solely in a DRIFT-derived spectra. Different vibrations, originating from the phosphorylated Ser side chain are of $\mathrm{P}=\mathrm{O}, \mathrm{P}-\mathrm{OH}$ and $\mathrm{P}-\mathrm{O}-\mathrm{C}$ major types. In the chosen $\mathrm{ROI}, \mathrm{P}=\mathrm{O}$ stretching $\left(1250-1300 \mathrm{~cm}^{-1}\right)$ and $\mathrm{P}-\mathrm{OH}$ deformation $\left(\approx 1050 \mathrm{~cm}^{-1}\right)$ vibrations [59] were currently not observed; $\mathrm{P}-\mathrm{OH}$ vibration was possibly masked by a more intense $\mathrm{P}-\mathrm{O}-\mathrm{C}$ stretching vibration 

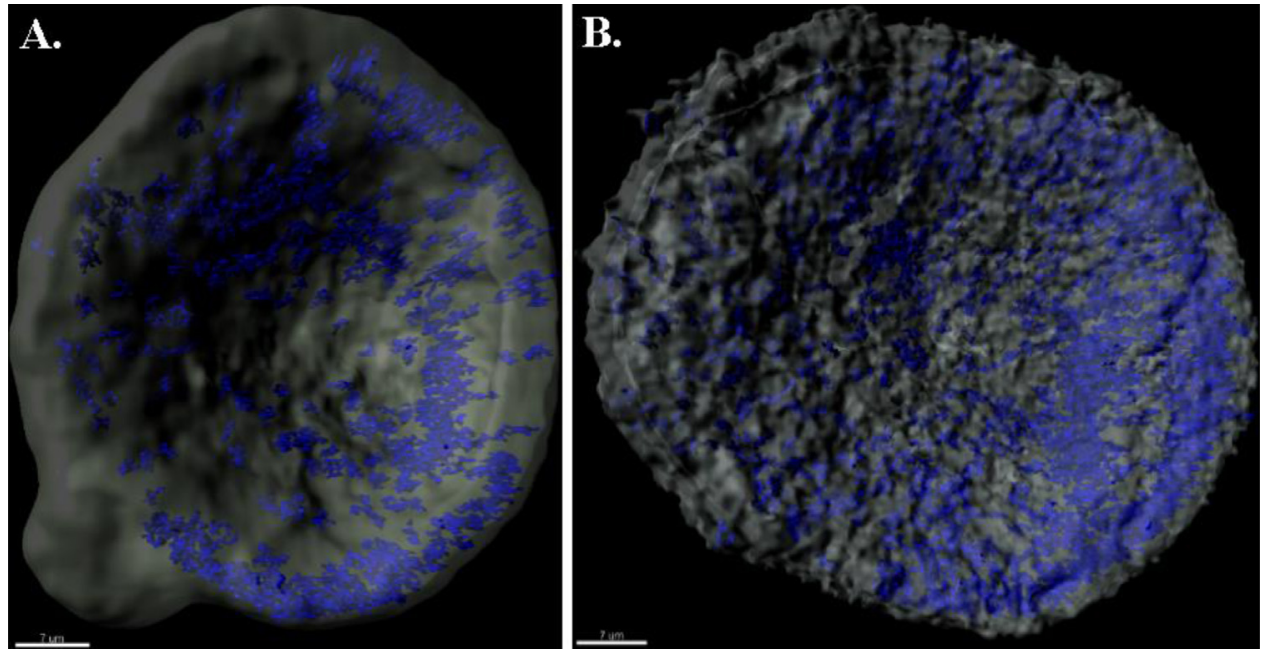

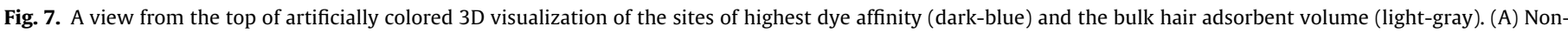

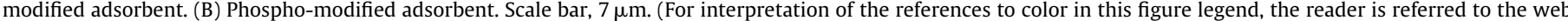
version of this article.)

[60] (aliphatic, 1000-1100 $\mathrm{cm}^{-1}$ ). P-O-C vibration itself was seen shifted, along with the appearance of Restrahlen band (Fig. 1A). Since DRIFT performance depends on diffuse, or volume, scattering, the size of abraded sample particles may provoke unwanted specular reflection, thus resulting in the observed artifact [61].

Phosphate incorporation was further confirmed by NMR analysis of protease-degraded hair keratin. Due to a subtle phosphorus amounts present in the sample, no additional salts were in used in the protease buffer formulation, as possible precipitation of phosphate could occur. Divalent metal cations like $\mathrm{Mg}^{+2}$ or $\mathrm{Ca}^{+2}$ are known to facilitate enzyme-driven reactions. Specifically, Esperase ${ }^{\circledR} 8.0$ L protease demonstrates enhanced stability and performance with $\mathrm{Ca}^{+2}$ ions present in reaction buffer [62]. However, no in vitro phosphorylation-specific peak was obtained for the digested hair samples, when calcium was present as buffer component (data not shown). Calcium phosphate salt formation and its subsequent precipitation at elevated temperature and $\mathrm{pH}$ may be accountable for that result [63]. The already mentioned presence of a weak peak in the negative control (Fig. 1B, lower panel) may stem from an in vivo post-translational modification of keratin. Indeed, such phosphorylation of several human hard $\alpha$-keratin and matrix proteins was previously visualized by immuno-blotting [38]. NMR studies, previously done on phosphorylated keratins, showed considerably low amounts of phosphate present within a tested samples [64,65].

One of the main outcomes of this study is that phosphatemodified adsorbent demonstrated higher affinity toward the dye adsorbate. Keratin is a polyampholyte with pI of 4.7-5.4 [66], so the charge deployed on it is $\mathrm{pH}$-dependent and negative at physiological $\mathrm{pH}$. The incoming phosphate group further enforces that negative charge, as its $\mathrm{p} K_{\mathrm{a} 2}=5.78$ [67], thus resulting in higher dye affinity to the hair and elevated $Q$ values (Figs. 2, 3, 4B, 6B).

At the same time, it can be seen that phosphorylation increases dye affinity to the adsorbent and decreases dye picking times. All the modeling outputs, presented in Table 1, clearly show the differences between the modified and the non-modified fibers. Another important feature of the made system is that the differences in dye adsorption are starting to be visible already from the 6th to 12th minutes of incubation (Fig. 3B), indicating rapid MB uptake by the phosphorylated fibers.

Concordantly with the approach that adsorption reaction models are widely employed to describe the process of adsorbent uptake, we tested three kinetic models. It was found that model fitting decreased as following: PSO > PFO > Intra-particle model. For both PSO and PFO models, the reaction rate-limiting step is the surface adsorption. In the case of PSO, for an observed system, MB removal from a solution and its deposition on hair is due to physicochemical interactions between the two phases (chemisorption). From the thermodynamic modeling, discussed later, it is clearly seen that the adsorption process is indeed of chemisorption type. On the contrary, PFO is thought to describe the dye deposition process by van der Waals forces between the dye and the hair (physisorption). Thus PFO model does not account for several adsorbate-related parameters and therefore is less accurate. Moreover, one of the deviations from the intra-particle model (Weber-Morris), used herein, represents another concept where the rate limiting step is the adsorbate diffusion through porous structure of adsorbent ([68] and references within). In some cases (as presented here and in the literature $[33,39]$ ), adsorbent boundary layer diffusion effects impose additional outcomes on the total adsorption process. Adsorption kinetics may thus be controlled by external diffusion in the bulk phase and intra-particle diffusion simultaneously. A non-zero slope of the fit curves, shown in Fig. S3, $C$ and a non-zero values of constant $C$ (Table 1 ) support the latter claim. However, the donation of intra-particle diffusion to the total process seem to be insufficient for that model to acquire superior $\bar{R}^{2}$ values.

Other important insights on dye-hair interactions are elucidated by isothermal modeling. Three models fit the acquired data in the descending order: Langmuir $>\mathrm{D}-\mathrm{R}>$ Freundlich. Apart of Langmuir isotherm assumptions (Section 2.3) there is an agreed opinion that the adsorption on solid surfaces, either physical or chemical, can be plausibly described by this model [41]. $Q_{\max }$ values, originating from this model, appear similar to the experimentally found (compare Tables 1 and 2). The effective dissociation coefficient $K_{\mathrm{L}}$ is a measure of adsorbate affinity to the adsorbent. Compared to the literature $([32,33,42,46]$ or Table 4$) K_{\mathrm{L}}$ demonstrates unusually high values, what may be perceived as irreversible dye binding, especially in the range of lower $[\mathrm{MB}]_{\text {init }}$ (Fig. 2, 0.05-0.35 $\mathrm{g} \mathrm{L}^{-1}$ ). $R_{\mathrm{L}}$ values for both adsorbent types indirectly support this notion, indicating more than just "favorable" adsorption. More recent studies on understanding the theoretical origins of empirical first- and second- order rate equations for adsorption showed that "the Langmuir kinetics indeed represents a hybrid rate equation with a variable reaction order of 1-2" [69]. This fact is important for understanding two outcomes: the relative plausibility of data fitting by 
the pseudo -first and-second kinetic models (Table 1) and the suitability of Langmuir model itself for the specific adsorption data set (Table 2). Nevertheless this does not mean that the observed adsorption is solely constituted by a particular mechanism. In fact, in many cases the experimental systems are comprised by porous and/or disperse solids, exhibiting structural and energetic heterogeneity. Accordingly, our system is expected to possess both non-uniformities: structural (originating from hair shaft perturbations) [30,54,55], and energetic (originating from phosphorylation) [67]. To accommodate for the energetic surface heterogeneity Freundlich and D-R models were employed [41]. Energetic surface heterogeneity is a depth change of the local potential minima as demonstrated by physically separated adsorption sites of that surface [70]. The values of $1 / n$, previously presented (Section 2.3), support the latter notion and are similar to the reported: lower than some [33,42] (indicating a more heterogenetic surface), or higher than others $[32,46]$ (indicating a less heterogenetic surface). Yet, on the basis of $k_{f}$, the adsorption capacity of our system was superior to the all others listed. Finally, the adsorption mechanism, clarified by $\mathrm{D}-\mathrm{R}$ model is of chemisorption type, corroborating the reports mentioned earlier. Another feature to be noted is that $Q_{\max }$ values seem to be overestimated by D-R isotherm, a common tendency seen also in the previous studies.

Of the thermodynamic values, calculated throughout the current work, $\Delta S$ attracts particular interest. This is due to a fact that estimations of both $\Delta H$ and $\Delta G$ for the very similar adsorption systems $[32,46]$ (Section 2.4) resulted in the same tendencies. Specifically for $\Delta G$ (Table 3), whose values neither fall to the range of pure physisorption ( -20 to $0 \mathrm{~kJ} \mathrm{~mol}^{-1}$ ) nor chemisorption $\left(-80\right.$ to $\left.-400 \mathrm{~kJ} \mathrm{~mol}^{-1}\right)$ [71], ion-exchange mechanism was proposed earlier in this work, on $E$ values basis (Section 3.4). The sole work dealing with MB uptake by virgin wool keratin, reports on significantly negative entropy change [46], while our study reports a slight positive change. Since both animal wool and human hair are very similar in structure and composition [72], there is a need to explain the observed discrepancy. It is known that positive entropic contributions upon binding mainly include the release of counter-ions, while negative contributions stem from the decreased mobility of adsorbates [73]. If one compares the oxidized keratin surface with the intact surface, the first is most probable to include various ions due to the oxidation by $\mathrm{H}_{2} \mathrm{O}_{2}$ originating radicals $\left(\mathrm{OH}^{\bullet}\right.$, ferryl radical). The radicals that emerge as $\mathrm{H}_{2} \mathrm{O}_{2}$ are reduced by a protein-bound metals [56], naturally occurring in the melanin granules of hair ( $\mathrm{Al}, \mathrm{Mg}, \mathrm{K}, \mathrm{Ca}, \mathrm{Fe}$ and $\mathrm{Zn}$ ) [74]. Some of the other mentioned adsorption systems, possessing ion exchange mechanism [42,48], exhibited positive $\Delta S$ values during the adsorbate uptake, thus making the explanation of the current observation quite plausible.

An interesting outcome was obtained from 3D imaging. As a highly heterogeneous material, the hair possesses sites of variable dye affinity, and this affinity can be somewhat increased by phosphorylation. However, it was not possible to discriminate between the phospho-sites and the rest, based on fluorescent microscopy. Hence only the totally increased amount of a bound MB, visualized by $3 \mathrm{D}$ reconstruction, provides additional support to the rest of experimental data, currently collected.

\section{Conclusions}

The performed study assessed hair keratin-based adsorption system, modified by in vitro phosphorylation. Our data support the notion that phosphorylation enhances the adsorption of cationic species, opening a possibility of a cosmetic application. Further research on enzymatic stability and specificity may enhance the concept of phosphorylation as a diversification mean for different natural materials in the future.

\section{Acknowledgements}

The authors would like to acknowledge the support, granted by the following projects: "BioEnv"-Biotechnology and Bioengineering for a sustainable world”, REF. NORTE-07-0124-FEDER-000048; and "Biolnd"-Biotechnology and Bioengineering for improved Industrial and Agro-Food processes", REF. NORTE-07-0124-FEDER000028. Both projects are co-funded by the Programa Operacional Regional do Norte (ON.2-O Novo Norte), QREN, FEDER.

\section{Appendix A. Supplementary data}

Supplementary data associated with this article can be found, in the online version, at http://dx.doi.org/10.1016/j.ijbiomac.2015. 12.082 .

\section{References}

[1] H.W. Heid, I. Moll, W.W. Franke, Patterns of expression of trichocytic and epithelial cytokeratins in mammalian tissues. I. Human and bovine hair follicles, Differentiation 37 (2) (1988) 137-157.

[2] A.L. Miranda-Vilela, A.J. Botelho, L.A. Muehlmann, An overview of chemical straightening of human hair: technical aspects, potential risks to hair fibre and health and legal issues, Int. J. Cosmet. Sci. 36 (February (1)) (2014) 2-11.

[3] C. Weathersby, A. McMichael, Brazilian keratin hair treatment: a review, J. Cosmet. Dermatol. 12 (2) (2013) 144-148.

[4] S. Reichl, Films based on human hair keratin as substrates for cell culture and tissue engineering, Biomaterials 30 (36) (2009) 6854-6866.

[5] L.R. Burnett, J.G. Richter, M.B. Rahmany, R. Soler, J.A. Steen, G. Orlando, T. Abouswareb, M.E. Van Dyke, Novel keratin (KeraStat) and polyurethane (Nanosan(R)-Sorb) biomaterials are hemostatic in a porcine lethal extremity hemorrhage model, J. Biomater. Appl. 28 (6) (2014) 869-879.

[6] S. Reichl, M. Borrelli, G. Geerling, Keratin films for ocular surface reconstruction, Biomaterials 32 (13) (2011) 3375-3386.

[7] P. Kar, M. Misra, Use of keratin fiber for separation of heavy metals from water, J. Chem. Technol. Biotechnol. 79 (11) (2004) 1313-1319.

[8] A. Mittal, Use of hen feathers as potential adsorbent for the removal of a hazardous dye, Brilliant Blue FCF, from wastewater, J. Hazard. Mater. 128 (2-3) (2006) 233-239.

[9] A. Aluigi, C. Tonetti, C. Vineis, A. Varesano, C. Tonin, R. Casasola, Study on the adsorption of chromium (VI) by hydrolyzed keratin/polyamide 6 blend nanofibres, J. Nanosci. Nanotechnol. 12 (9) (2012) 7250-7259.

[10] R.D. King, B.E. Brockway, Treatment of wool materials, in Google Patents, T.U.O., Reading, Editor: GB, 1988.

[11] X. Huang, R.K. Kobos, G. Xu, Peptide-based carbon nanotube hair colorants and their use in hair colorant and cosmetic compositions, DE, 2005.

[12] M.S. Norman, J.P. David, L.B. Peter, Covalent Bonding of Active Agents to Skin, Hair or Nails, Chesebrough-Pond's USA Co., Division of Conopco, Inc., Greenwich, CT, US, 1996.

[13] H. Green, G.D. Corey, B.J. Compton, P. Dijan, Attaching agents to tissue with transglutaminase and a transglutaminase substrate, US, 2001.

[14] M.M. Fernandes, A.C. Gomes, A. Vasconcelos, F.D. Munteanu, T. Tzanov, M.S. Goncalves, N. End, K.U. Schoening, G.M. Guebitz, A. Cavaco-Paulo, Protein disulphide isomerase-assisted functionalization of keratin-based matrices, Appl. Microbiol. Biotechnol. 90 (4) (2011) 1311-1321.

[15] M. Fernandes, A. Cavaco-Paulo, Protein disulphide isomerase-assisted grafting of cysteine-containing peptides, Biocatal. Biotransform. 30 (1) (2012) 10-19.

[16] K. Brown, B.P. Murphy,.LJ. Wolfram, Hair dyeing process and compositons package, US, 1992.

[17] J. Kawase, K. Ukaji, E. Nagashima, Hair treatment composition, bleaching composition and hair color tone modifier composition, US, 1991.

[18] H.D. Boswell, J.M. Marsh, J.S. Park, M.A. Olshavsky, Compositions suitable for the treatment of hair comprising chelants and methods for reducing oxidative hair damage, US, 2007.

[19] A. Guerra-Tapia, E. Gonzalez-Guerra, Hair cosmetics: dyes, Actas Dermosifiliogr. 105 (9) (2014) 833-839.

[20] D.J. Mandell, I. Chorny, E.S. Groban, S.E. Wong, E. Levine, C.S. Rapp, M.P. Jacobson, Strengths of hydrogen bonds involving phosphorylated amino acid side chains, J. Am. Chem. Soc. 129 (4) (2007) 820-827.

[21] F.H. Westheimer, Why nature chose phosphates, Science 235 (4793) (1987) 1173-1178.

[22] P. Strnad, R. Windoffer, R.E. Leube, Induction of rapid and reversible cytokeratin filament network remodeling by inhibition of tyrosine phosphatases, J. Cell Sci. 115 (Pt 21) (2002) 4133-4148. 
[23] J. Liao, L.A. Lowthert, N.O. Ku, R. Fernandez, M.B. Omary, Dynamics of human keratin 18 phosphorylation: polarized distribution of phosphorylated keratins in simple epithelial tissues, J. Cell Biol. 131 (5) (1995) 1291-1301.

[24] M. Pekny, E.B. Lane, Intermediate filaments and stress, Exp. Cell Res. 313 (10) (2007) 2244-2254.

[25] T.T. Sun, H. Green, Keratin filaments of cultured human epidermal cells. Formation of intermolecular disulfide bonds during terminal differentiation, J. Biol. Chem. 253 (6) (1978) 2053-2060.

[26] M. Inagaki, Y. Gonda, M. Matsuyama, K. Nishizawa, Y. Nishi, C. Sato, Intermediate filament reconstitution in vitro. The role of phosphorylation on the assembly-disassembly of desmin, J. Biol. Chem. 263 (12) (1988) 5970-5978.

[27] A. Dabrowski, Adsorption-its development and application for practical purposes, in: A. Dabrowski (Ed.), Adsorption and its Applications in Industry and Environmental Protection: Applications in Industry, Elsevier Science Ltd., Netherlands, 1998, pp. 3-16.

[28] A. Dabrowski, Theoretical foundations of physical adsorption from binary non-electrolytic liquid mixtures on solid surfaces: present and future, Adv Colloid Interface Sci. 27 (3-4) (1987) 211.

[29] M.I. El-Khaiary, Least-squares regression of adsorption equilibrium data: comparing the options, J. Hazard. Mater. 158 (1) (2008) 73-87.

[30] M. Fernandes, A. Cavaco-Paulo, Protein disulphide isomerase-mediated grafting of cysteine-containing peptides onto over-bleached hair, Biocatal. Biotransform. 30 (1) (2012) 10-19.

[31] V. Volkov, A. Vasconcelos, M.P. Sarria, A.C. Gomes, A. Cavaco-Paulo, Phosphorylation of silk fibroins improves the cytocompatibility of silk fibroin derived materials: a platform for the production of tuneable material, Biotechnol. J. 9 (10) (2014) 1267-1278.

[32] A. Aluigi, F. Rombaldoni, C. Tonetti, L. Jannoke, Study of methylene blue adsorption on keratin nanofibrous membranes, J. Hazard. Mater. 268 (2014) $156-165$.

[33] H. Chen, J. Zhao, J. Wu, G. Dai, Isotherm, thermodynamic, kinetics and adsorption mechanism studies of methyl orange by surfactant modified silkworm exuviae, J. Hazard. Mater. 192 (1) (2011) 246-254.

[34] A. Barth, C. Zscherp, What vibrations tell us about proteins, Q. Rev. Biophys. 35 (4) (2002) 369-430.

[35] A.P. Negri, H.J. Cornell, D.E. Rivett, A model for the surface of keratin fibers, Text. Res. J. 63 (2) (1993) 109-115.

[36] F. Fathi, F. Lagugné-Labarthet, D.B. Pedersend, H.-B. Kraatz, Studies of the interaction of two organophosphonates with nanostructured silver surfaces, Analyst 137 (19) (2012) 4448-4453.

[37] M.S. Anderson, J.M. Andringa, R.W. Carlson, P. Conrad, W. Hartford, M. Shafer, A. Soto, A.I. Tsapin, J.P. Dybwad, W. Wadsworth, K. Hand, Fourier transform infrared spectroscopy for Mars science, Rev. Sci. Instrum. 76 (034101)(2005) $1-9$.

[38] A. Nakamura, M. Arimoto, K. Takeuchi, T. Fujii, A rapid extraction procedure of human hair proteins and identification of phosphorylated species, Biol. Pharm. Bull. 25 (5) (2002) 569-572.

[39] N. Kannan, M.M. Sundaram, Kinetics and mechanism of removal of methylene blue by adsorption on various carbons-a comparative study, Dyes Pigm. 51 (1) (2001) 25-40.

[40] G. Ran, Y. Zhang, Q. Song, Y. Wang, D. Cao, The adsorption behavior of cationic surfactant onto human hair fibers, Colloids Surf. B: Biointerfaces 68 (1) (2009) $106-110$.

[41] A. Dabrowski, Adsorption-from theory to practice, Adv. Colloid Interface Sci. $93(1-3)(2001) 135-224$

[42] H. Chen, J. Zhao, G. Dai, Silkworm exuviae-a new non-conventional and low-cost adsorbent for removal of methylene blue from aqueous solutions, J. Hazard. Mater. 186 (2-3)(2011) 1320-1327.

[43] S.K. Papageorgiou, F.K. Katsaros, E.P. Kouvelos, J.W. Nolan, H. Le Deit, N.K. Kanellopoulos, Heavy metal sorption by calcium alginate beads from Laminaria digitata, J. Hazard. Mater. 137 (3) (2006) 1765-1772.

[44] J.P. Hobson, Physical adsorption isotherms extending from ultrahigh vacuum to vapor pressure, J. Phys. Chem. 73 (8) (1969) 2720-2727.

[45] F. Helfferich, Ion Exchange, McGraw-Hill Book Co. Inc., New York, 1962.

[46] A.R. Khan, H. Tahir, F. Uddin, H. Uzma, Adsorption of methylene blue from aqueous solution on the surface of wool fiber and cotton fiber, J. Appl. Sci. Environ. Manag. 9 (2) (2005) 29-35.

[47] L. Gao, H. Gao, Haematoxylin sorption onto yak hair: kinetic and thermodynamic studies, Color. Technol. 130 (1) (2014) 21-26.
[48] D. Suteu, T. Malutan, Industrial cellolignin wastes as adsorbent for removal of methylene blue dye from aqueous solutions, BioResources 8 (1) (2013) 427-446.

[49] G. Akkayaa, F. Güzel, Application of some domestic wastes as new low-cost biosorbents for removal of methylene blue: kinetic and equilibrium studies, Chem. Eng. Commun. 201 (4) (2014) 557-578.

[50] A.Z. Aroguz, J. Gulen, R.H. Evers, Adsorption of methylene blue from aqueous solution on pyrolyzed petrified sediment, Bioresour. Technol. 99 (6) (2007) 1503-1508.

[51] S. Winkler, D. Wilson, D.L. Kaplan, Controlling beta-sheet assembly in genetically engineered silk by enzymatic phosphorylation/dephosphorylation, Biochemistry 39 (41) (2000) 12739-12746.

[52] V. Volkov, M.P. Sarria, A.C. Gomes, A. Cavaco-Paulo, Phosphorylated silk fibroin matrix for methotrexate release, Mol. Pharm. 12 (1) (2015) 75-86.

[53] H.N. Bramson, E.T. Kaiser, A.S. Mildvan, Mechanistic studies of cAMP-dependent protein kinase action, CRC Crit. Rev. Biochem. 15 (2) (1984) 93-124.

[54] M.L. Tate, Y.K. Kamath, S.B. Ruetsch, H.-D. Weigmann, Quantification and prevention of hair damage, J. Soc. Cosmet. Chem. 44 (6) (1993) 347-371.

[55] N. Ali, R.R. Zohra, S.A.U. Qader, M. Mumtaz, Accepted article, Int. J. Cosmet. Sci. (2015), http://dx.doi.org/10.1111/ics.12201.

[56] E. Shacter, Protein oxidative damage, Methods Enzymol. 319 (2000) 428-436

[57] L.J. Wolfram, Human hair: a unique physicochemical composite, J. Am. Acad. Dermatol. 48 (Suppl. 6) (2003) S106-S114.

[58] T. Armaroli, T. Bécue, S. Gautier, Diffuse reflection infrared spectroscopy (Drifts): application to the in situ analysis of catalysts, Oil Gas Sci. Technol. 59 (2) (2004) 215-237.

[59] L.J. Bellamy, L. Beecher, The infra-red spectra of organo-phosphorus compounds. Part II. Esters, acids, and amines, J. Chem. Soc. (1952) 1701-1706

[60] L. Bellamy, The infrared spectra of some organophosphorus esters, J. Chem. Soc. (1952) 475-483.

[61] J.W. Salisbury, A. Wald, The role of volume scattering in reducing spectral contrast of reststrahlen bands in spectra of powdered minerals, Icarus 96 (1) (1992) 121-128.

[62] D.R. Durham, D.B. Stewart, E.J. Stellwag, Novel alkaline- and heat-stable serine proteases from alkalophilic Bacillus sp. strain GX6638, J. Bacteriol. 169 (6) (1987) 2762-2768

[63] O. Mekmene, S. Quillard, T. Rouillon, J-M. Bouler, M. Piot, F. Gaucheron, Effects of $\mathrm{pH}$ and $\mathrm{Ca} / \mathrm{P}$ molar ratio on the quantity and crystalline structure of calcium phosphates obtained from aqueous solutions, Dairy Sci. Technol. 89 (3-4) (2009) 301-316.

[64] P.L. Yeagle, J. Frye, B.S. Eckert, Phosphorylation modulates keratin structure Biochemistry 29 (6) (1990) 1508-1514.

[65] B.S. Eckert, P.L. Yeagle, Site-specificity of ethanol-induced dephosphorylation of rat hepatocyte keratins 8 and 18: a 31P NMR study, Cell Motil. Cytoskeleton 33 (1) (1996) 30-37.

[66] R.C. Marshall, Characterization of the proteins of human hair and nail by electrophoresis, J. Invest. Dermatol. 80 (6) (1983) 519-524.

[67] M. Śmiechowski, Theoretical $\mathrm{p} K_{\mathrm{a}}$ prediction of $O$-phosphoserine in aqueous solution, Chem. Phys. Lett. 514 (4-6) (2015) 123-129.

[68] Y.S. Ho, J.C.-Y. Ng, G. McKay, Kinetics of pollutant sorption by biosorbents: review, Sep. Purif. Rev. 29 (2) (2000) 189-232.

[69] Y. Liu, L. Shen, From Langmuir kinetics to first- and second-order rate equations for adsorption, Langmuir 24 (20) (2008) 11625-11630.

[70] B. Charmas, R. Leboda, Effect of surface heterogeneity on adsorption on solid surfaces. Application of inverse gas chromatography in the studies of energetic heterogeneity of adsorbents, J. Chromatogr. A 886 (1-2) (2000) $133-152$.

[71] M.J. Jaycock, G.D. Parfitt, Chemistry of Interfaces, Ellis Horwood Ltd. Onichester, 1981.

[72] J. Menkart, L.J. Wolfram, I. Mao, Caucasian hair, negro hair, and wool: similarities and differences, J. Soc. Cosmet. Chem. 17 (13) (1966) 769-788.

[73] S.L. Turgeon, C. Schmitt, C. Sanchez, Protein -polysaccharide complexes and coacervates, Curr. Opin. Colloid Interface Sci. 12 (4-5) (2007) 166-178.

[74] T. Imai, The influence of hair bleach on the ultrastructure of human hair with special reference to hair damage, Okajimas Folia Anat Jpn. 88 (1) (2011) 1-9. 